\title{
Osteoblast response to zirconia surfaces with different topographies
}

\author{
H.M.T.U. Herath ${ }^{1}$, L. Di Silvio ${ }^{2}$, J.R.G. Evans ${ }^{3 *}$ \\ ${ }^{1}$ Department of Medical Laboratory Science, Faculty of Allied Health Sciences, University of Peradeniya, Sri Lanka. \\ ${ }^{2}$ Guy’s, King’s and St Thomas' Medical and Dental Institute, King’s College London, \\ London SE1 9RT, UK. \\ ${ }^{3}$ Department of Chemistry, University College London, 20 Gordon Street, London WC1H 0AJ
}

\begin{abstract}
Zirconia - 3 mol.\% yttria ceramics were prepared with as-sintered, abraded, polished, and porous surfaces in order to explore the attachment, proliferation and differentiation of osteoblast-like cells. After modification, all surfaces were heated to $600{ }^{\circ} \mathrm{C}$ to extinguish traces of organic contamination. All surfaces supported cell attachment, proliferation and differentiation but the surfaces with grain boundary grooves or abraded grooves provided conditions for enhanced initial cell attachment. Nevertheless, overall cell proliferation and total DNA were highest on the polished surface. Zirconia sintered at a lower temperature $\left(1300^{\circ} \mathrm{C}\right.$ vs. $\left.1450{ }^{\circ} \mathrm{C}\right)$ had open porosity and presented reduced proliferation as assessed by AlamarBlue ${ }^{\mathrm{TM}}$ assay, possibly because the openness of the pores prevented cells developing a local microenvironment. All cells retained the typical polygonal morphology of osteoblast-like cells with variations attributable to the underlying surface notably alignment along the grooves of the abraded surface.
\end{abstract}

Keywords: cell culture; zirconia; osteoblast; topography, biocompatibility

\section{*Corresponding author}

Prof. J.R.G. Evans, Department of Chemistry, University College London, 20 Gordon Street, London WC1H 0AJ

E mail: j.r.g.evans@ucl.ac.uk

T.P. 44 (0)20 76794689 


\section{Introduction}

Zirconia is a polymorphic, nearly inert ceramic oxide [1] often used in situations requiring high temperature, high wear resistance or compatibility with steels for which it is closely matched in thermal expansion [2]. Its relative chemical inertness, combined with its deployment as a biomaterial makes it a useful choice to explore the relative importance of surface chemical and topographical influences on cell adhesion and development. Indeed it has been found in some cases to provide higher levels of adhesion, proliferation and differentiation than titanium surfaces [3] though other comparisons with titanium find the reverse [4]. Several techniques involving etching and particle impact can be used to change topography and wettability [5]. A recent study involving isotropic abrasion of both $316 \mathrm{~L}$ stainless steel and TiAl6V4 and introduction of human mesenchymal stem cells found no statistical effect of roughness on cell number or coverage at $48 \mathrm{~h}$ [6]. The main applications as a biomaterial are for femoral heads for total hip replacement where it has been used for more than a decade [7] and dental implants. With submicron grain size and appropriate stabilizing oxide, it retains the tetragonal phase in a transformable state after sintering, forming tetragonal zirconia polycrystal (TZP) with a theoretical density of $6080 \mathrm{~kg} \mathrm{~m}^{-3}$ in the case of $3 \mathrm{~mol} \%$ yttria stabilisation as used here [8]. The high toughness is caused by expansion to monoclinic in the 'process zone' ahead of the advancing crack which has the effect of local compressive pre-stressing. Its continued use was threatened in 2001-2002 by a series of service failures traced to the ageing of TZP initiated by steam sterilization [9]. Although unanticipated in applications for femoral heads, the ageing effect is well known to be due to surface transformation of tetragonal grains to monoclinic and is controlled by the choice of initial particle size, composition and processing conditions [10]. Many compositional interventions to prevent it have been established [11,12].

Zirconia is considered to be nearly bio-inert [13] and its use in dental and medical implants takes advantage of its high fracture toughness $\left(5-10 \mathrm{MPa}{ }^{1 / 2}\right.$ ) rather than its biocompatibility which means that if it is prepared without introducing manufacturing defects it can present very high strength $(\sim 1 \mathrm{GPa})$.

Anselme and Bigerelle's review [14] with 319 citations, presents an overall assessment of the role of surface topography on cell attachment to biomaterials. One general conclusion is that attachment and adhesion of bone cells are enhanced by surface roughness but correlation with roughness amplitude measurements is poor. The morphology of the roughness is a more significant factor [15]. Meyle et al. have shown that even small changes in roughness prompt cell responses [16]. On the other hand, cell proliferation is not unambiguously correlated with surface roughness. Anselme and Bigerelle [14] find that in the majority of studies, proliferation was increased on 
smooth surfaces. They raise the concern that surface chemistry modification resulting from changing the surface roughness may influence the results.

An experimental difficulty is that interventions to change surface roughness often produce surface chemical changes; adsorbed species from polishing for example could form residues that interfere with initial adsorbed protein conformation. In this study, all surfaces were heated to $600^{\circ} \mathrm{C}$ after surface modification in an attempt to achieve surface chemical conformity. Like the oxygen plasma and UV treatments suggested for zirconia [17] this should also remove hydrocarbons. The aim is to explore the surface preparation of zirconia on the early stages of osteoblast attachment and development.

\section{Experimental Details}

Zirconia (HSY3, ex Daichii Kigenso, Japan) in the as-milled, non-spray dried form was used (surface area $5.8 \mathrm{~m}^{2} / \mathrm{g}$ by BET analysis, Micrometrics Gemini II 2370, Gosford NSW, Australia). The sub-micron particles are fine, equiaxed, of uniform ultimate particle diameter and agglomerated at the micron scale as shown in Figure 1.

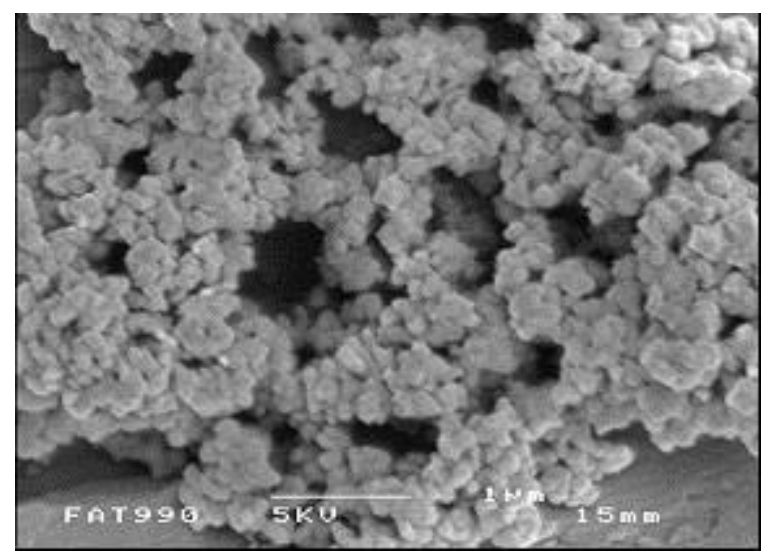

Figure 1. SEM image of zirconia showing sub-micron equiaxed particles (scale bar represents $1 \mu \mathrm{m})$.

Discs were slip cast in cylindrical moulds of $20 \mathrm{~mm}$ diameter, $6 \mathrm{~mm}$ height from an aqueous suspension of 18 vol. \% powder (57.1 wt.\%), prepared by sonication for 10 minutes using an ultrasonic probe (U200S, IKA Labortechnik, Germany) and stabilised with 1 wt.\% Darvan C (R.T.Vanderbilt Norwalk, Connecticut, USA) based on the mass of powder. The spray-dried version of this powder is suitable for compaction but this form is suitable for slip casting which requires a homogenously dispersed suspension as free as possible from agglomeration [18]. Slip 
casting was chosen in preference to compaction because it does not produce the inter-agglomerate voids characteristic of compaction processes [19].

The suitability of the dispersant at this level of addition was assessed by conducting sedimentation tests at low solids loading (<1 vol. \%). As shown in Figure 2, after 86 ks (24 hours), the cloudy layer was high at $87 \%$ of the initial height. The long-term sediment height after $1.2 \mathrm{Ms}$ (14 days) was low (6\%) indicating a well-packed sediment and the supernatant remained slightly cloudy to $90 \%$ of it height. These three attributes are indicative of a well dispersed, non-flocculating system [20].

After casting and drying, the apparent density was $2540 \mathrm{~kg} \mathrm{~m}^{-3}$ or $42 \%$ of theoretical obtained from the mass and dimensions of cast regular cylinders. The firing conditions, determined from sintering trials at various temperatures, were $1450{ }^{\circ} \mathrm{C}$ at a rate of $5{ }^{\circ} \mathrm{C} / \mathrm{min}$ with a soak time of 2 hours. Density was measured by Archimedes' method using a Mettler Toledo - 33360210260 balance attachment. Some discs were also sintered at $1300{ }^{\circ} \mathrm{C}$. Surfaces that had been sintered at $1450{ }^{\circ} \mathrm{C}$ were used as sintered, abraded $(100 \mu \mathrm{m})$ and polished $(1 \mu \mathrm{m})$ for cell culture studies after they had been cleaned. The cleaning procedure consisted of washing in 'analytical grade' ethanol with further sonication and then heating to $600{ }^{\circ} \mathrm{C}$ in air to remove traces of organic matter.

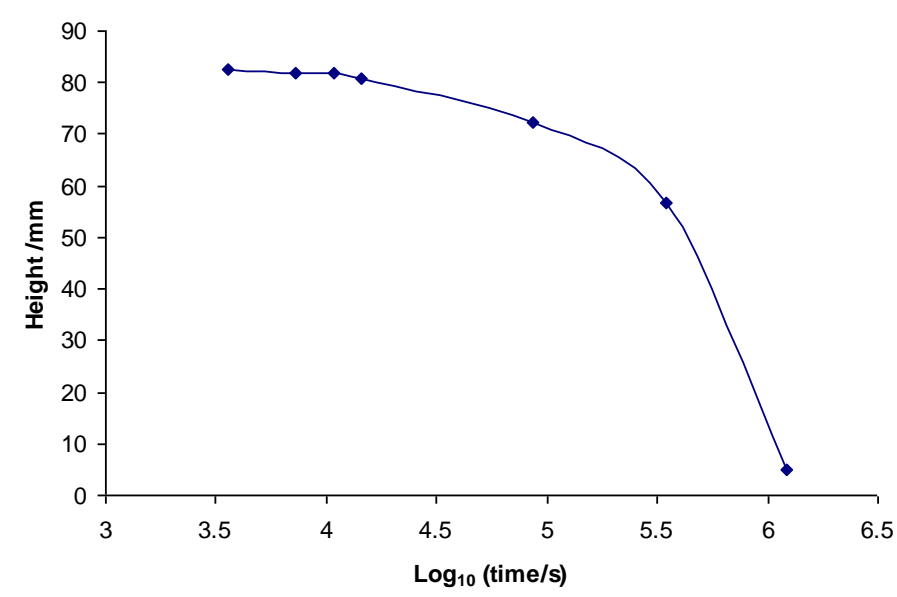

Figure 2. Sedimentation of zirconia suspension at 1 vol.\% (Initial height: $82.5 \mathrm{~mm}$ ).

A human osteosarcoma cell-line (HOS TE85, ECACC No. 87070202) was used. Cells were cultured in Dulbecco's modified Eagle's medium (DMEM) (Life Technologies, Paisley UK), supplemented with $10 \%$ foetal calf serum (FCS), $1 \%$ non-essential amino acids, $150 \mu \mathrm{g} / \mathrm{ml}$ ascorbic acid, $0.02 \mathrm{mM}$ L-glutamine, $0.01 \mathrm{M}$ HEPES, 100 units $\mathrm{m}^{-1}$ penicillin and 100 units $\mathrm{ml}^{-1}$ streptomycin. Thermanox ${ }^{\text {TM }}$ cover slips (TMX, Life Technologies, Paisely, UK) were used as the tissue culture control. HOS cells were seeded at a density of $2 \times 10^{5}$ cells ml $^{-1}$ on test and control materials. The culture plates were incubated at $37^{\circ} \mathrm{C}$ in a humidified atmosphere with $5 \% \mathrm{CO}_{2}$. The 
culture medium was replaced at intervals chosen to minimize the disturbance of the culture conditions.

Samples were prepared for microscopy by seeding with HOS cells at a density of $2 \times 10^{5}$ cells $\mathrm{ml}^{-1}$ and incubating at $37{ }^{\circ} \mathrm{C}$ in humidified air with $5 \% \mathrm{CO}_{2}$. After 24,48 and 168 hours of incubation, the cultures were fixed with $1.5 \%$ glutaraldehyde buffered in $0.1 \mathrm{M}$ sodium cacodylate, stained in $1 \%$ osmium tetroxide and $1 \%$ tannic acid buffer and dehydrated using a series of aqueous alcohol solutions starting from $20 \%-70 \%$ in $10 \%$ increments. They were stained in $0.5 \%$ uranyl acetate and further dehydrated in $90 \%, 96 \%$ and then $100 \%$ ethyl alcohol (containing $\mathrm{Na}_{2} \mathrm{CO}_{3}$ ) and with hexamethyl-di-salazane and finally air dried. The cultures were palladium coated for examination in the scanning electron microscope (Joel JSM 5500LV, Japan) in duplicate at each time point for observation of cellular morphology and attachment.

The cell viability and cytotoxic effects of the material was determined by performing MTT assay. Extracts were prepared by eluting test samples in complete medium at $37{ }^{\circ} \mathrm{C}$ for $1,5,7,14$, 21 and 28 days. HOS cells were cultured in the extracts at $37{ }^{\circ} \mathrm{C}$ in a humidified air at $5 \% \mathrm{CO}_{2}$ for 24 hours and further 4 hour incubation in the presence of 10\% MTT [3-(4,5- dimethylthiazol - 2 yl) -2,5 --diphenyltetrazolium bromide] (Sigma Aldrich Ltd, UK). Dimethyl sulfoxide (DMSO) was added after removing the medium and mixed for 10 minutes to ensure complete dissolution of crystals. Absorbance was measured on Dynatech MR700 micro plate reader, at a test wavelength of $570 \mathrm{~nm}$ and reference wavelength of $630 \mathrm{~nm}$.

AlamarBlue $^{\mathrm{TM}}$ assay was performed to evaluate the cell proliferation. HOS cells were seeded on test materials at a density of $2 \times 10^{6}$ cells $\mathrm{ml}^{-1}$ and were incubated at $37{ }^{\circ} \mathrm{C}$ in humidified air with $5 \% \mathrm{CO}_{2}$ for $1,5,7,14,21$, and 28 days. The spent culture medium was replaced at regular intervals with care to minimise the disturbance of the culture conditions. At each time point the medium was removed from all the test wells. One $\mathrm{ml}$ of $10 \%$ alamarBlue $^{\mathrm{TM}}$ (Serotech, UK), diluted in phenol-red free medium was added to each well and incubated at $37{ }^{\circ} \mathrm{C}$ in a humidified air at $5 \%$ $\mathrm{CO}_{2}$ for 4 hours. The absorbance was read at $570 \mathrm{~nm}$ with a reference wavelength of $630 \mathrm{~nm}$ in the Dynatech plate reader (DIAS Micro-titre plate reader, W. Sussex, UK) after removing 8 x $100 \mu 1$ aliquots from the original well to a 96 well plate. The remaining alamarBlue ${ }^{\mathrm{TM}}$ was removed from the wells after the incubation period and the wells were washed twice with PBS. All the wells were replaced with fresh culture medium and were further incubated. This was carried out serially for 1 , $5,7,14,21$ and 28 days of incubation.

Fluorimetric assay was performed to determine the total DNA content. Cells were lysed at each time point (i.e. day $1,7,14,21$ and 28) using freeze/thaw cycle $\left[4\right.$ cycles $\mathrm{x}\left(-70^{\circ} \mathrm{C}\right.$ for 20 minutes $/ 37^{\circ} \mathrm{C}$ for 20 minutes)]. These lysates and standards were reacted with $1 \mu \mathrm{g} \mathrm{ml}^{-1}$ of DNA specific fluorescent dye Hoechst 33285. The DNA standards, obtained from calf thymus (Sigma 
Chemicals) were used to obtain a standard curve with a concentration range of $0,0.31,0.62,1.25$, 2.5, 5, 10 and $20 \mu \mathrm{g} \mathrm{ml}^{-1}$. The amount of DNA present in the samples was determined from the standard curve. Fluorescence was measured on a Fluoroscan fluorimeter (Ascent, Life Sciences International) at an excitation and emission wavelengths of $355 \mathrm{~nm}$ and $450 \mathrm{~nm}$, respectively.

Cell differentiation of osteoblastic phenotype was determined by measuring the ALP production of HOS cells. The cells were lysed on days $1,7,14,21$ and 28 by freeze/ thaw $\left[4\right.$ cycles $x\left(-70^{\circ} \mathrm{C}\right.$ for 20 minutes $/ 37^{\circ} \mathrm{C}$ for 20 minutes)] method. P-nitrophenol phosphate in a diethanolamine buffer (Merck, UK) was used as the substrate. The ALP activity was determined by measuring the reaction product, yellow coloured p-nitrophenol at a wavelength of $405 \mathrm{~nm}$ using COBAS-BIO centrifugal analyser (Roche, UK).

The phenotypic marker, osteocalcin was detected by using a competitive ELISA which detects intact (de-novo) OC in cell lysates. Twenty-five micro-litres of reconstituted standards, controls and samples were added to each strip well of 96 micro-titre plate (Metra ${ }^{\mathrm{TM}}$ Quidel Corporation, USA), coated with osteocalcin purified from human bone. This first step was completed within 30 minutes. These test samples and standards were reacted with $125 \mu$ of anti-osteocalcin (purified murine monoclonal anti-osteocalcin antibody) for 2 hours at room temperature. The wells were washed manually with wash buffer (non-ionic detergent in a buffered solution). Each well was filled with 150 $\mu l$ reconstituted enzyme conjugate (lyophilised goat anti-mouse IgG antibody conjugated to alkaline phosphatase) and incubated for 60 minutes at room temperature. After washing with wash buffer, 150 $\mu \mathrm{l}$ of the working substrate solution (p-nitrophenol phosphate) was added to each well and incubated for $35-40$ minutes. The reaction was stopped with $50 \mu$ stop solution, $1 \mathrm{~N} \mathrm{NaOH}$. The optical density was read against $405 \mathrm{~nm}$ (DIAS Micro-titre plate reader, W. Sussex, UK) and the concentration of samples and controls were determined from the standard curve.

BIORAD method was done to quantify the total protein content. Cells were lysed at each time point using freeze/thaw cycle $\left[4\right.$ cycles $\mathrm{x}\left(-70^{\circ} \mathrm{C}\right.$ for 20 minutes $/ 37^{\circ} \mathrm{C}$ for 20 minutes $)$ ]. $200 \mu \mathrm{l}$ from each sample and controls were pipetted into the 96 well plates (Nunc, Germany). Finally, 40 $\mu \mathrm{l}$ of Coomassi ${ }^{\circledR}$ Brilliant Blue G-250 dye reagent (Sigma Chemicals) was added to each well. The plate was covered with a plate sealer and was mixed vigorously on a plate shaker at room temperature for 10 minutes to ensure that the well contents were thoroughly mixed. The plate was read on a Biorad (3550, Japan) micro-plate reader at a wavelength of $595 \mathrm{~nm}$.

Nodules formed due to minearlaization of the matrix, were detected by using the histological preparation of vonKossa staining. Von Kossa stains black in mineralised nodules. Surfaces were washed well in distilled water and were covered with $2 \%$ silver nitrate and were exposed to bright light (sun light) for $20-60$ minutes. The surfaces were washed in several changes of distilled water 
and were treated with $2.5 \%$ sodium thiosulphate for 2 minutes. Finally, the samples were washed well in tap water and were blotted and dried before examined under microscope.

\section{Results and Discussion}

\subsection{Electron microscopy}

$\mathrm{ZrO}_{2}-\mathrm{Y}_{2} \mathrm{O}_{3}$ ceramics have a wide sintering temperature range between $1400{ }^{\circ} \mathrm{C}-1600{ }^{\circ} \mathrm{C}$ and had closed porosity but exaggerated grain growth was visible in samples sintered for 3 hours at $1450{ }^{\circ} \mathrm{C}$ (Figure 3(a)). During final stage sintering at high temperatures, grain growth can lead to appearance of the monoclinic phase and mechanical weakening [21]. After 2 hours at $1450{ }^{\circ} \mathrm{C}$, discs having very few pores and relative density of $99 \%$ were obtained without large grains (Figure 3 (b)). Samples sintered at $1300{ }^{\circ} \mathrm{C}$ had open porosity and low relative density (Figure 3(c)). These samples were used for cell culture experiments to compare with dense sintered, abraded and polished surfaces. They present considerable surface rugosity but another important difference is that they have open pore channels so that diffusion and convective flow of liquids is possible. In a closed pore, a cell which has covered the entrance, has considerable control of its local environment. Thus while the mechanical properties of the low density material may limit its use, it nevertheless provides an interesting comparison to the closed porosity materials. Surfaces sintered at $1450{ }^{\circ} \mathrm{C}$ and subsequently abraded with $100 \mu \mathrm{m}$ grit, had grooves providing a coarse and oriented texture (Figure 3(d)). 


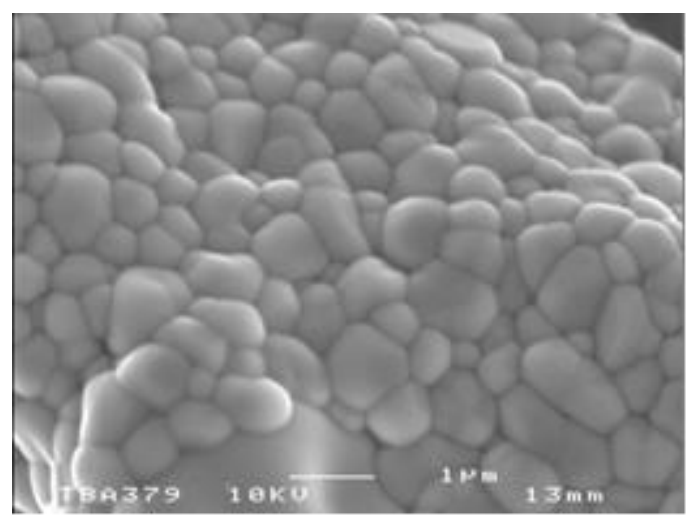

(a)

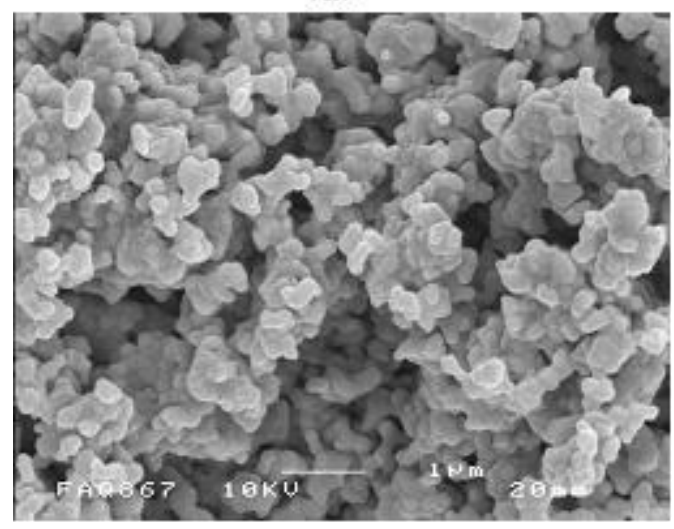

(c)

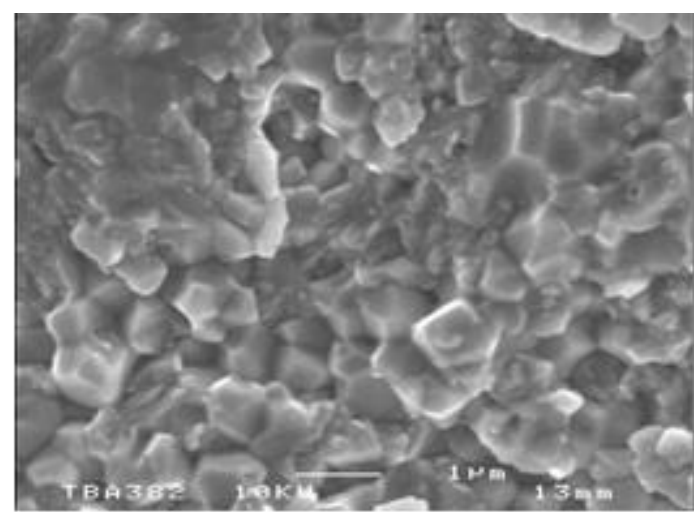

(b)

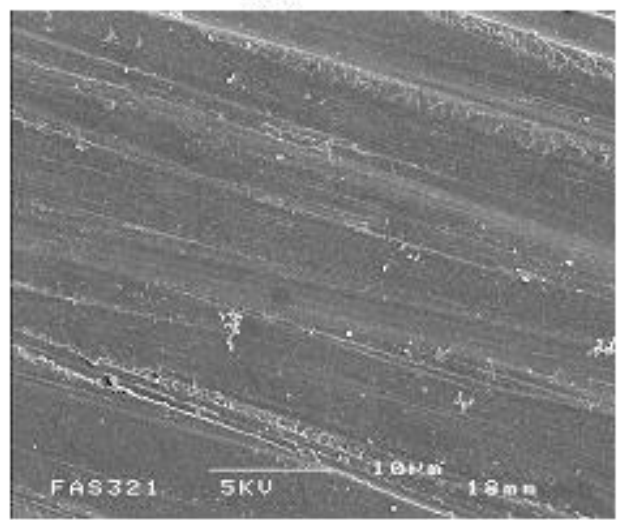

(d)

Figure 3. SEM images of sintered zirconia: (a) surface sintered at $1450{ }^{\circ} \mathrm{C}$ for 3 hours showing exaggerated grain growth (note large grain lower centre) (b) fracture surface after sintering at 1450 ${ }^{\circ} \mathrm{C}$ for 2 hours indicated no large grains (c) fracture surface after sintering at $1300{ }^{\circ} \mathrm{C}$ for 1 hour (open porosity) and (d) dense $\left(1450^{\circ} \mathrm{C} / 2 \mathrm{hr}\right.$ ) zirconia abraded on $100 \mu \mathrm{m} \mathrm{SiC}$.

Cells on all zirconia surfaces maintained the typical polygonal shape with some morphological deviations as described by Di Silvio [22], resulting from response to the surface characteristics [23]. HOS cells attached to the Thermanox control were stretched across the surface with extended cytoplasmic processes after 24 hours. Lamellipodia attached to the zirconia made the cells flat and well spread. On the highly porous zirconia surface (sintered at $1300{ }^{\circ} \mathrm{C}$ ) cells were more rounded in shape and tended to form colonies. The abraded surface was covered by cells after 24 hours of incubation, the cell margins were merged and it was difficult to define their perimeters or detect the underlying material. However, there was a much lower density of initial attachment of cells to the polished surface while the cytoplasm of cells had thinned and they were elongated but scattered on the surface without preferred orientation. This has been noted previously [24], moreover, Wieland et al. demonstrated that osteoblast-like cells spread more extensively and were flatter on smooth surfaces than on rough surfaces. Unlike the abraded surface, areas devoid of cells were visible at 24 hours of culture on the polished zirconia resulting from lower density of initial attachment. 
After 48 hours of incubation, the cells on all the surfaces except the polished surface were approaching confluence (Figure 4). In Giljean's work [6] a statistical insignificance of surface roughness obtained from profilometry was recorded at $48 \mathrm{~h}$. Cells on the polished surface, which were smooth and flattened, had spread extensively covering approximately $75 \%$ of the surface area and resembling those on the TMX control which is also a smooth surface. They were randomly oriented and there were areas on the material that were free of cell attachment and hence provided space for further proliferation and spreading. The clustered cells on the porous zirconia spread laterally making it difficult to differentiate their margins but the underlying material was still visible at 48 hours. Cells on the rough, porous surface continued to have more rounded morphology compared with those on the smooth surfaces. Osteoblasts are known to appear flattened on some surfaces but have a more three dimensional morphology on others [24]. Wieland and co-workers [23], showed that osteoblast cells paralleled fibroblasts in response to rough surfaces by exhibiting significantly greater thickness of the cytoplasm.

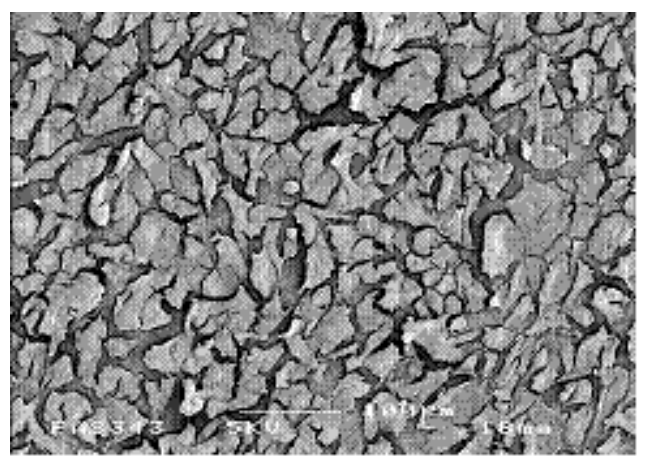

(a)

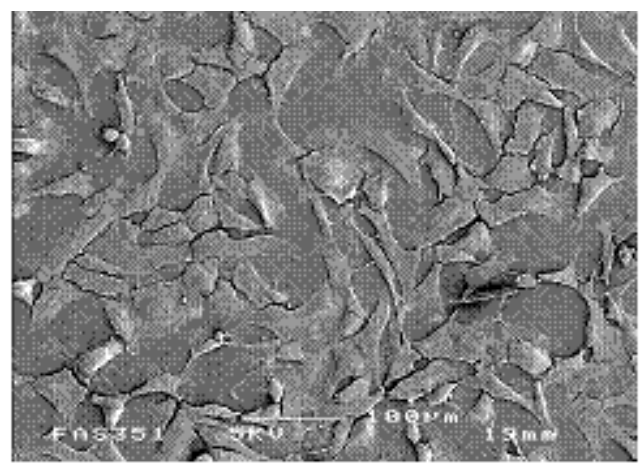

(b)

Figure 4. Scanning electron micrographs of HOS cell attachment to surfaces after 48 hours of incubation (a) abraded and (b) polished. (scale bars represent $100 \mu \mathrm{m}$ ).

The cells on all surfaces were confluent and closely packed after 168 hours of incubation (day 7) at which stage the individual morphology of cells was difficult to distinguish and cell perimeters were at confluence making a continuous sheath over the surfaces. Rounded cells were present which may be cells undergoing division indicative of proliferation. Cells on abraded surfaces were oriented along the grooves as observed previously on a grooved titanium substrate with human osteoblast-like cells [26] and as clearly seen in Figure 5(a) where confluence is accompanied by alignment. Cells attached to the polished surface reached confluence but needed up to 168 hours to compensate for the initial lower population density. Surface topography affects interactions between osteoblasts and implant [27] and the samples with roughness in the form of pores, grain boundary grooves or abrasion grooves promote early cell attachment compared to the polished surface. However, once the initial attachment of cells had occurred, the subsequent 
proliferation on the smooth surface of polished zirconia was enhanced and a dense growth of cells was observed after 168 hours (Figure 5 (b)) which resembled that of the control.

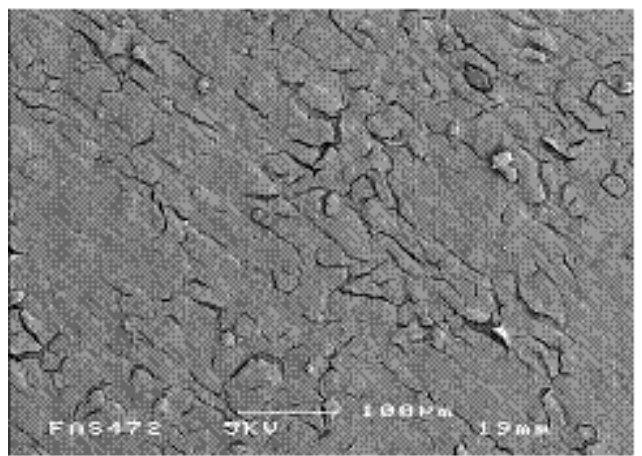

(a)

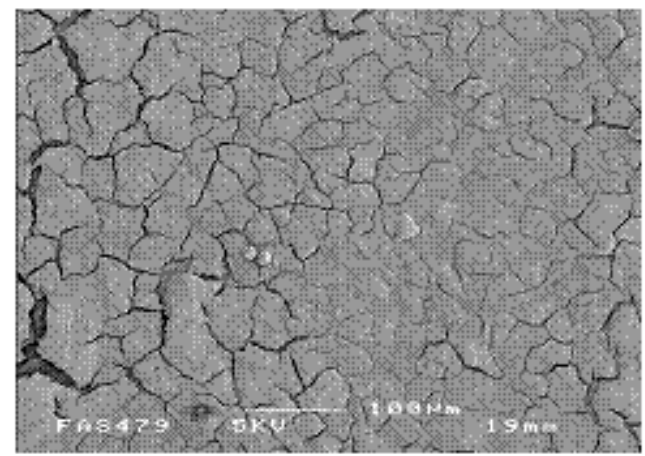

(b)

Figure 5. Scanning electron micrographs of HOS cell attachment and confluence on zirconia surfaces at 168 hours of incubation (a) abraded and (b) polished (scale bar represents $100 \mu \mathrm{m}$ ).

Differences in the spreading directions of cytoplasmic processes were evident at higher magnification: cells adherent to the control surface tended to produce filopodia scattered in all directions while cells were more rounded in shape and had fewer and shorter filopodia on rough, porous zirconia. Longer retracting fibres were seen on rounded-up cells which may have been preparing for cell division. On the dense sintered surfaces, cells were more flattened and elongated than those on porous surfaces but the length of filopodia was comparable. Cells on abraded surfaces tended to align along the grooves and filopodia were oriented along a single direction (Figure 6(a)). The body of the cells demonstrated a fusiform morphology resembling that of fibroblast cells. Cytoplasmic processes were confined to the terminal ends of the body of the cell. Few were found on the lateral edges due to the inhibition of filopodia to extend when they meet discontinuities: contact guidance. Anselme et al. [26] note that in the process of differentiation, cells tend to find a state in which internal and external forces are balanced inducing an aligned morphology. In such instances, confronted by a ridge or obstruction, lamellipodia which contain actin micro-spikes would not give rise to actin polymerization. This forms elongated cells which orient along the groove direction as seen here. Furthermore, the terminal edges of the filopodia were enlarged when they form a firm attachment (Figure 6 (b)). 


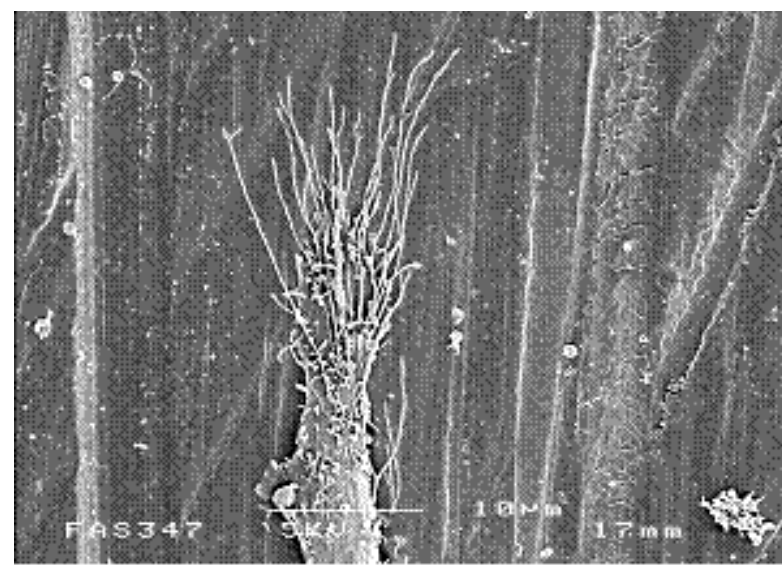

SEM images of HOS ce (a) a abraded zirconia: (a) cells tend to align (b) grooves and (b) terminal ends of filopodia enrarge.

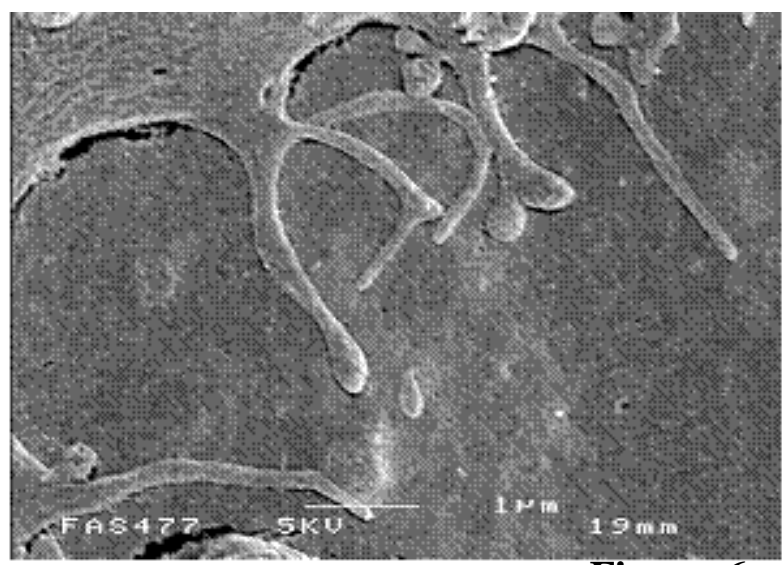

Figure 6.

HOS cells on the polished surface were flattened, the cytoplasm was thin (Figure 7(a)) and there was no preferred orientation of the body of the cell. Unlike cells on abraded surfaces, the cytoplasmic processes of cells attached to polished surfaces were not confined to a distinct area of the cell but projected out from the whole cell surface. On the polished surface, the enlarged structures at the distal end of the extended filopodia were more distinct (Figure 7(b)) than those on the abraded surface. These modifications of processes may have the purpose of promoting adhesion to the polished substrate. Designated 'fingering' by Aboushelib et al. [28], the same effect was observed on their polished zirconia samples.
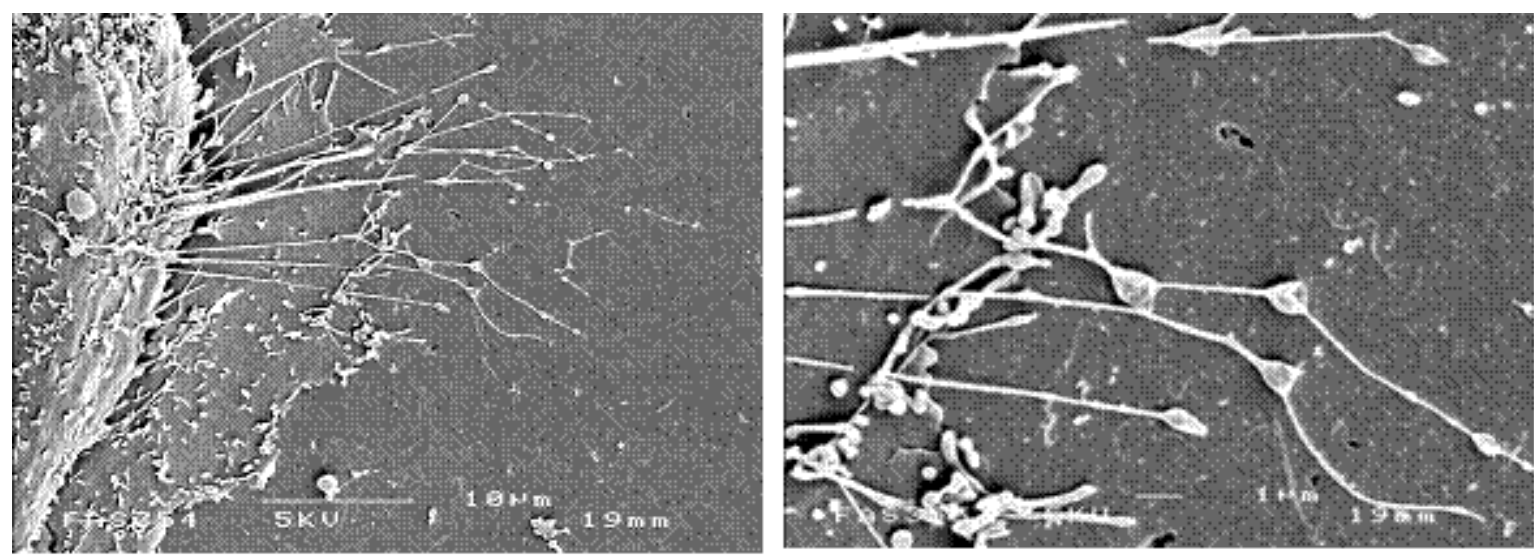

Figure 7. SEM ir (a) f cells on polished zirconia: (a) cells w_(b) (b) extensions of filopodia terminal ends.

The microscopy demonstrates that the original polygonal morphology of osteoblast cells and their responses differed according to the substrate microstructure. The cells which were dorsoventrally flattened with thin cytoplasm showed random orientation on polished surfaces whereas those on abraded surfaces were more round with thick cytoplasm and were aligned along a single direction. Furthermore, initial cell adhesion and spreading were most effective on the abraded 
surface and cells adherent to the polished surfaces required a longer period (168 hours) to reach confluence.

\subsection{Cytotoxicity}

MTT assay confirms that zirconia was not toxic to cell membranes (Figure 8). This is a rapid and versatile colorimetric assay, based on the tetrazolium salt MTT which measures living cells quantitatively as the tetrazolium ring is cleaved in active mitochondria [29] and its appropriateness for measuring cytotoxicity to cells has been established [30-32]. Mosmann [29] shows that MTT is cleaved by all living, metabolically active cells but not by dead cells or erythrocytes. High levels of metabolic activity were observed in cells attached to sintered zirconia at days 1 to 28 as shown by comparison with the positive and negative control surfaces.

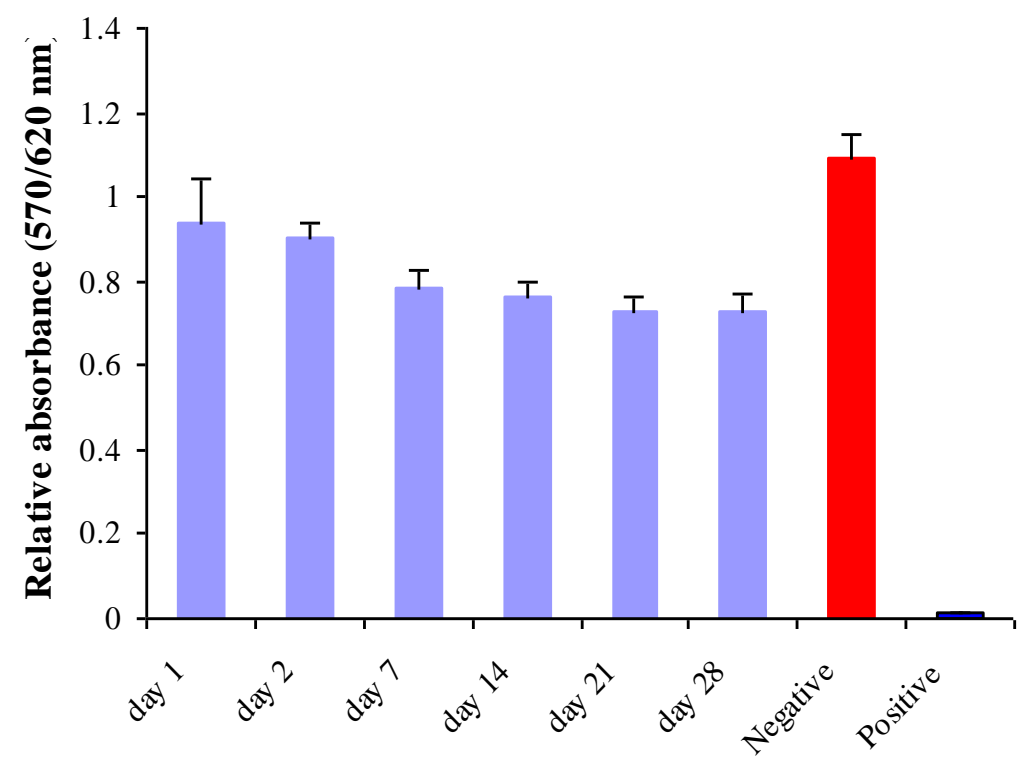

Figure 8. MTT assays up to 28 days for the negative (TMX) and positive control (ethanol) and zirconia sintered at $1450^{\circ} \mathrm{C} / 2 \mathrm{hrs}$. (Arithmetic means, error bars represent $95 \%$ confidence intervals and $\mathrm{n}=8)$.

\subsection{Cell Growth and Proliferation}

The trend in cell proliferation on the zirconia surfaces measured using Alamarblue ${ }^{\mathrm{TM}}$ [3336] throughout the period was similar to that of the control (Figure 9) but at a lower level. At day 14 , there was a reduction in proliferation on all surfaces including control with recovery to the original levels at day 21 . The polished surface, on which low recruitment was attributed to the difficulty of cell attachment and adhesion, presented a marked increase in proliferation at days 21 and 28. This is in agreement with the general trend seen in Anselme's review [14]: smooth surfaces show reduced initial cell adhesion but increased proliferation. Despite the high level of initial cell 
recruitment and cell spreading on abraded surfaces which was demonstrated by microscopy, cell proliferation was relatively poor. The polished surface supported the highest level of cell proliferation towards the latter part of the study period, results which are consistent with SEM imaging. Cell proliferation on the $1450{ }^{\circ} \mathrm{C}$ sintered surface was only slightly higher than that on the $1300{ }^{\circ} \mathrm{C}$ surface. Hence although all the surfaces promoted HOS cell proliferation, the polished surface was better in supporting long term proliferation.

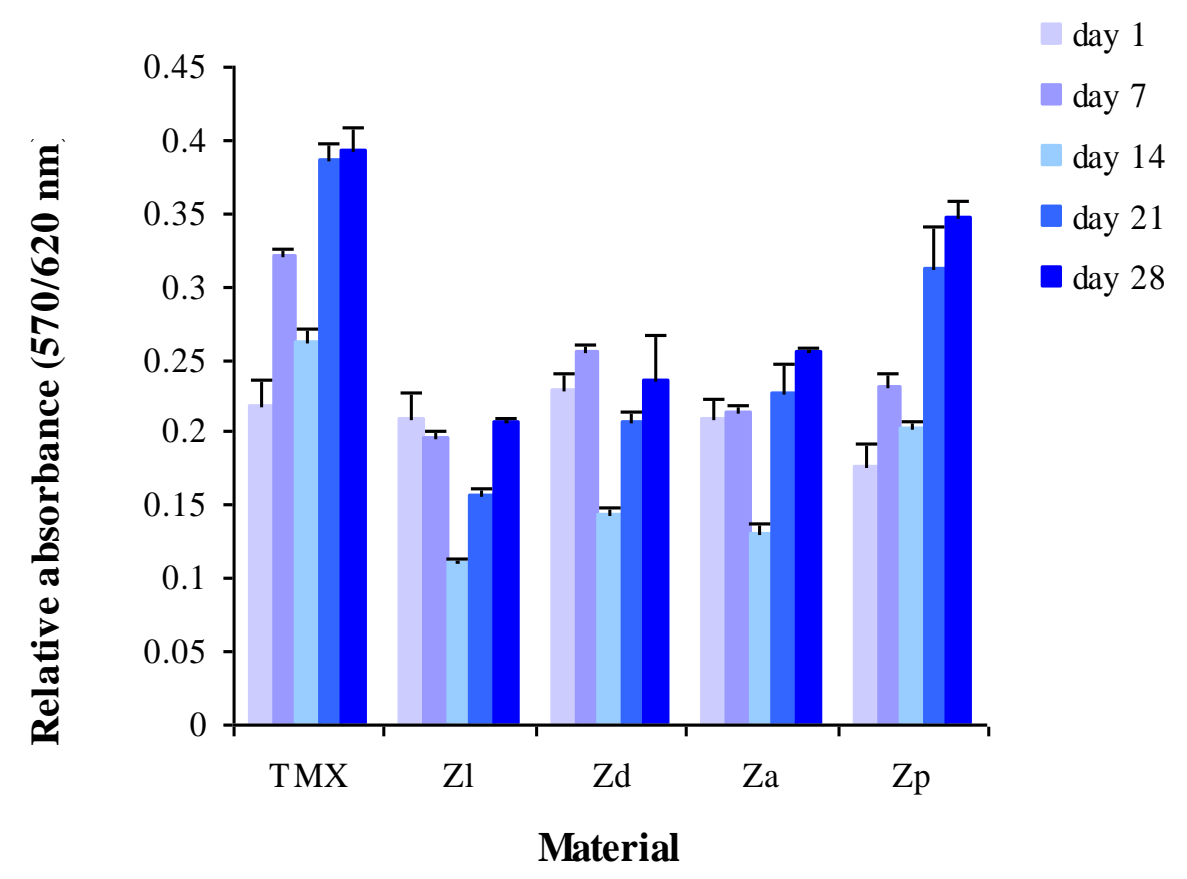

Figure 9. AlamarBlue ${ }^{\mathrm{TM}}$ assayfor cell proliferation up to 28 days of incubation for the control and zirconia: Z1:as sintered at $1300{ }^{\circ} \mathrm{C}$, Zd: as sintered at $1450{ }^{\circ} \mathrm{C}$, Za: abraded and Zp: polished. (Arithmetic means, error bars represent $95 \%$ confidence intervals and $n=8$ ).

\subsection{Total DNA}

Measurement of total DNA (Figure 10) showed that cell proliferation on zirconia followed a similar trend to that of the control, TMX. The highest DNA level excluding control, towards the latter part of the study was again shown by cells attached to the polished surface, confirming the fact that the smooth surface promoted long term cell proliferation, compared to the as-sintered and abraded surfaces. 


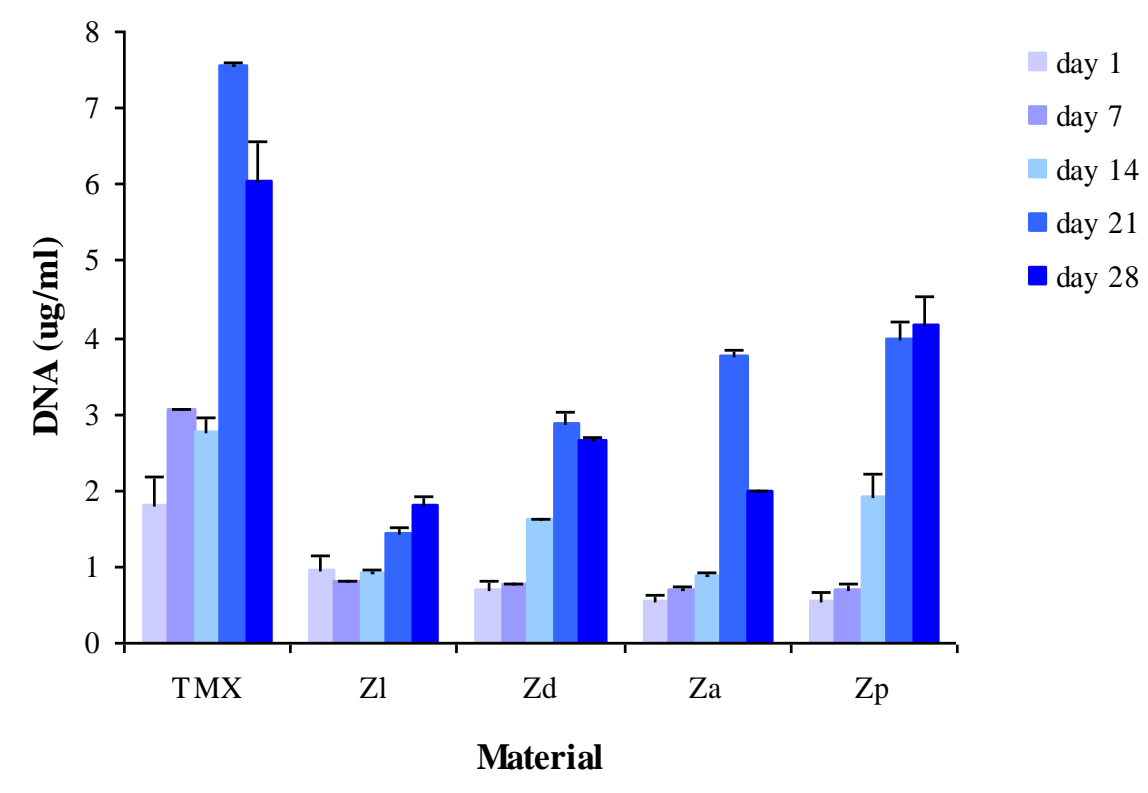

Figure 10. Total DNA of cells up to 28 days of incubation attached to the negative (TMX) control and zirconia. Z1: as sintered at $1300{ }^{\circ} \mathrm{C}, \mathrm{Zd}$ : sintered at $1450{ }^{\circ} \mathrm{C}, \mathrm{Za}$ : abraded $(\mathrm{Za})$ and $\mathrm{Zp}$ : polished. (Arithmetic mean, error bars represent $95 \%$ confidence interval and $n=4$ ).

The alamarblue ${ }^{\mathrm{TM}}$ and DNA assays demonstrate that all zirconia surfaces promoted cell proliferation throughout the study period. Initial cell recruitment and proliferation play an important role. Zirconia sintered at $1450{ }^{\circ} \mathrm{C}$ with grain boundary grooves and the abraded surface with coarser elongated grooves promoted higher levels of initial cell attachment compared to the polished surfaces. Anselme [14] comments on an emerging view that osteoblasts developing on a rough surface can create a microenvironment that enhances new bone development, an idea that is consistent with the results for the abraded surface as well as explaining the lower performance of the much rougher $1300{ }^{\circ} \mathrm{C}$ zirconia which has open porosity which allows flow-through thus denying the cell the ability to control the local environment. Nevertheless, despite the lower initial levels of cell attachment to the polished surface, cell proliferation measured by alamarBlue ${ }^{\mathrm{TM}}$ and DNA, as well as expression of osteocalcin enhanced after day 21: the cells on the polished surface, as it were, catch up.

\subsection{Cell Phenotype and Differentiation}

The expression of ALP, an early marker of cell differentiation [37], was detected in the early stages from cells on all zirconia surfaces (Figure 11). The peak occurs at day 14 or day 21 on most surfaces and is associated with a large error bar: ALP expression decreases thereafter. This is not the case for the highly porous structure sintered at $1300^{\circ} \mathrm{C}$ which has very low levels and presents no maximum. When Figures 10 and 11 are compared, a high indicator of differentiation tends to be associated with a reduction in cell proliferation. It has previously been shown that a decrease in cell 
proliferation usually coincided with an increase of differentiation and vice versa [38]. The polished surface supported the maximum differentiation while the highly porous sample sintered at $1300{ }^{\circ} \mathrm{C}$ demonstrated the lowest. However by day 21, the expression of ALP had become lower for all the surfaces indicating down regulation of cell differentiation.

Osteocalcin, a late marker of osteoblast differentiation and an early indicator of mineralization was up-regulated once the ALP activity reached the maximum levels (Figure 11), as previously shown by Di Silvio [22]. The highest level of osteocalcin production was observed in the cells attached to the polished surface (Figure 11(d)) while the lowest was produced by cells on the $1300{ }^{\circ} \mathrm{C}$ samples (Figure 11(a)). The expression of this protein on abraded and surfaces as-sintered at $1450{ }^{\circ} \mathrm{C}$ was comparable (Figure $11(\mathrm{c} \& \mathrm{~b})$ ). These results indicate that cells attached to all the zirconia surfaces were able to produce osteocalcin confirming a differentiated cell population and signs of mineralization.
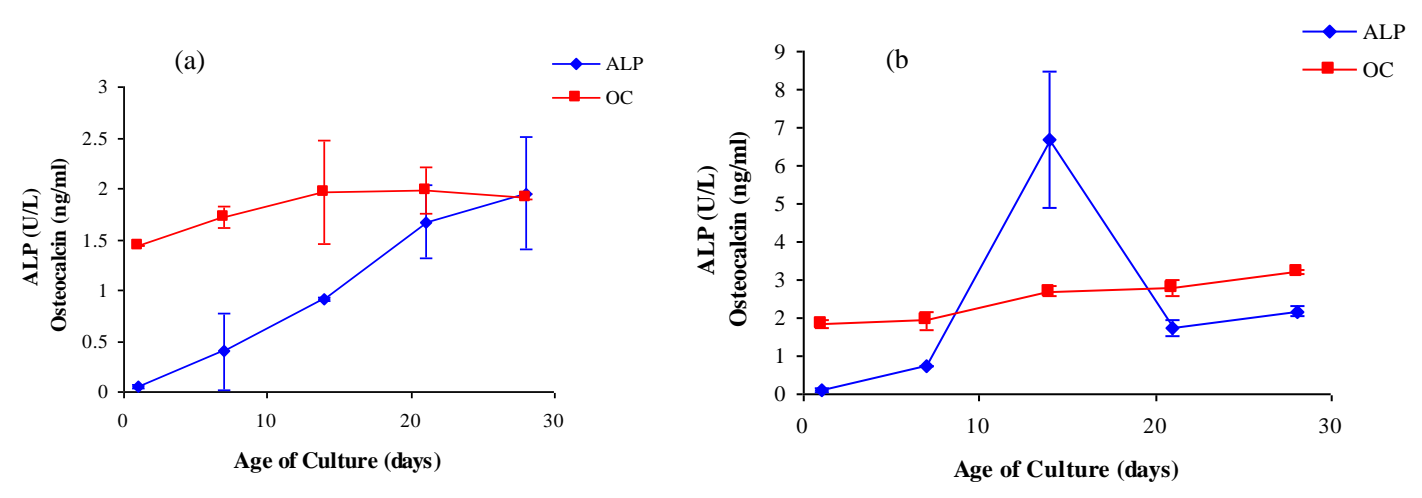

(d)
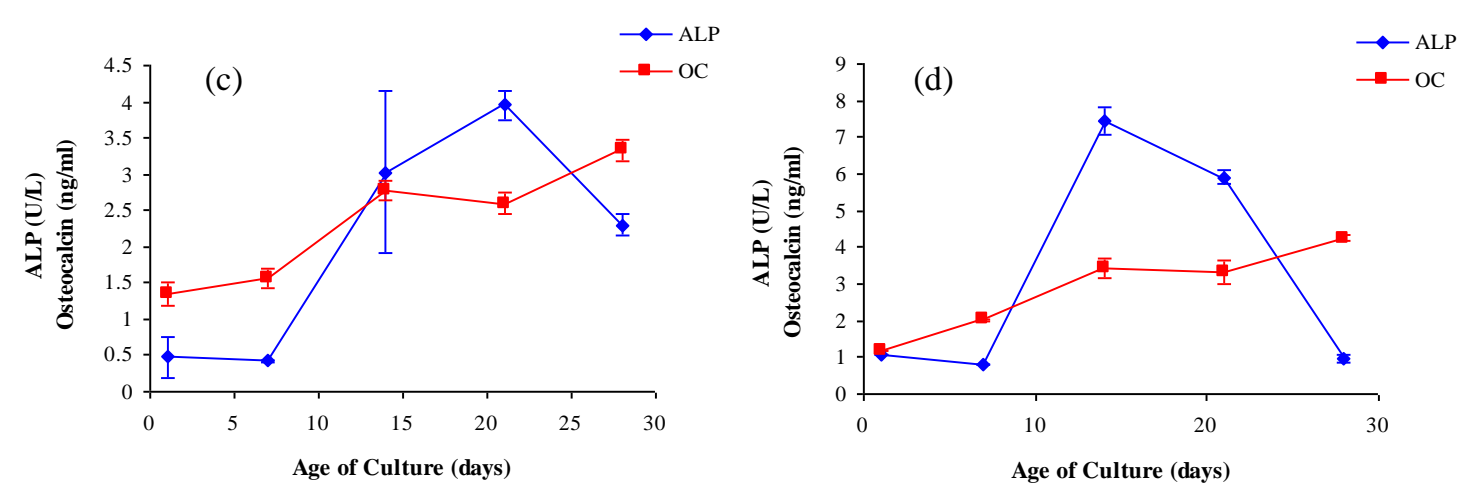

Figure 11. Expression of ALP and Osteocalcin of HOS cells attached to as sintered surfaces of zirconia: (a) sintered at $1300{ }^{\circ} \mathrm{C}$, (b) sintered at $1450{ }^{\circ} \mathrm{C}$ (c) abraded and (d) polished.

\subsection{Total protein content}


The total protein contents were high for all the samples beyond 168 hours (day 7) and were comparable to the control (Figure 12). The high and consistent levels for zirconia sintered at $1300^{\circ} \mathrm{C}(\mathrm{Zl})$ which has open porosity is likely to be brought about by adsorption of additional protein from the medium on the ceramic surface.

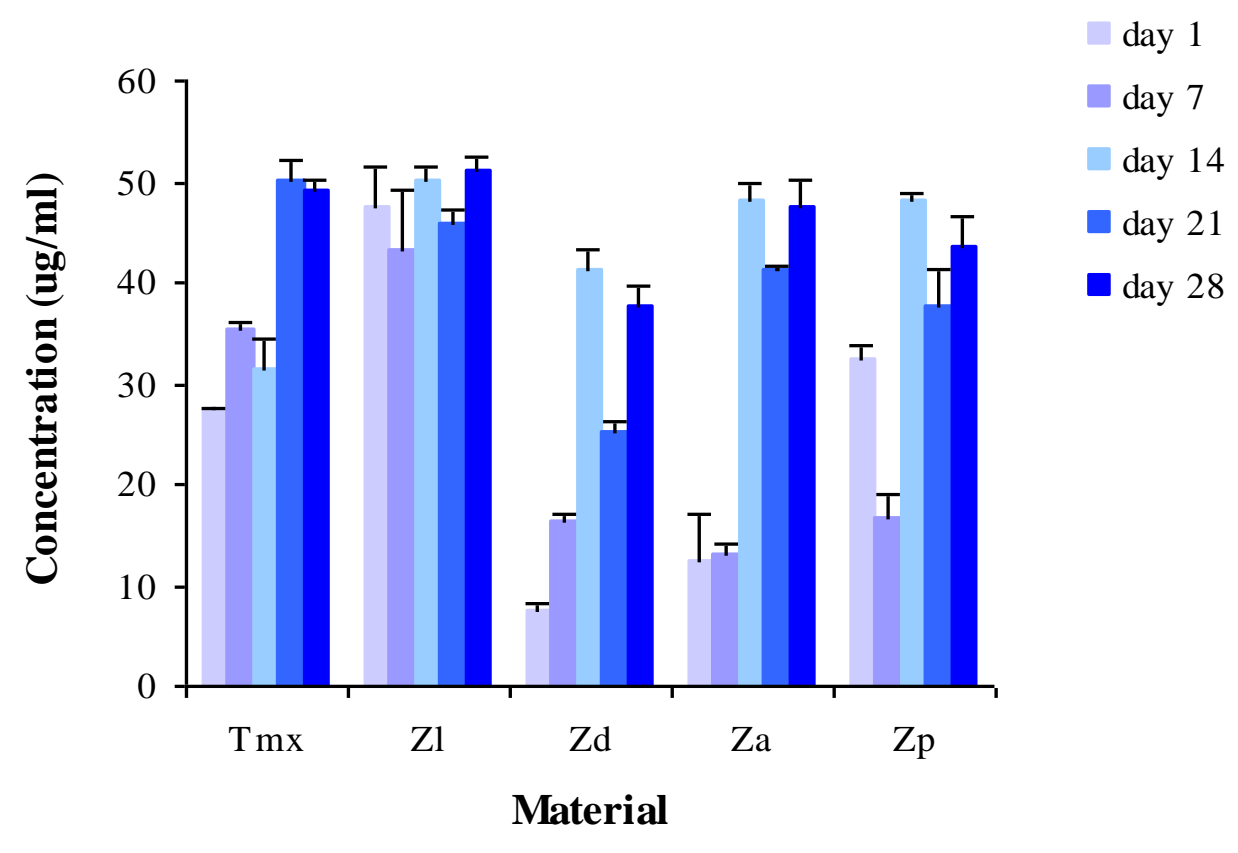

Figure 12. Total protein content of HOS cells cultured on negative control (TMX) and zirconia up to 28 days of incubation. $\mathrm{Z1}$ : sintered at $1300{ }^{\circ} \mathrm{C}, \mathrm{Zd}$ : sintered at $1450{ }^{\circ} \mathrm{C}, \mathrm{Za}$ : abraded and $\mathrm{Zp}$ : polished. (Arithmetic means, error bars represent $95 \%$ confidence intervals and $n=4$ ).

The increase observed at day 14 may have been a cumulative effect of increased ALP production in addition to high protein levels produced by proliferating cells. The zirconia samples sintered at $1450{ }^{\circ} \mathrm{C}$ show similar protein levels among which the abraded surface presents slightly higher levels overall.

The zirconia surfaces were able to promote nodule formation after 35 days of incubation without supplements to enhance bone formation. The surfaces that produced the highest level of OC tended to have poor nodule formation and vice-versa. This non-collagenous gammacarboxyglutamic acid-containing anionic protein is associated with the calcification process showing high affinity for calcium and hydroxyapatite [39]. Furthermore, it is an inhibitor of HA growth in-vitro while regulating $\mathrm{Ca}$ homeostasis. Hence, these results can be explained by $\mathrm{OC}$ binding $\mathrm{Ca}$ ions as well as retarding crystal growth of hydroxyapatite when this protein was in high concentrations. 
HOS type cells were presented in vitro to zirconia surfaces which were chemically identical but topologically different. All surfaces supported attachment and proliferation of HOS cells without eliciting a toxic response. All cells retained the typical polygonal morphology of osteoblastlike cells with variations attributable to the underlying surface topography. Since all surfaces were cleaned and then treated by heating to $600^{\circ} \mathrm{C}$ prior to cell culture, differences of surface chemistry, for example those resulting from the tenacious attachment of hydrocarbons were not responsible for the results. Surfaces with sintered grain boundary grooves and abraded grooves showed higher levels of initial cell attachment but polished surfaces had higher levels of proliferation and total DNA by the end of the study.

Markers for osteoblast function confirmed the retention of osteoblastic phenotype on all four surfaces while indicating the onset of mineralization. All surfaces supported the development of nodules. When low sintering temperature was used to obtain zirconia with open porosity, cell proliferation was relatively low, possibly reflecting the inability of cells to establish a microenvironment. In this case, the total protein content measurement was confounded by protein adsorbed from the medium on the high surface area of the ceramic. The overall results demonstrated that long term cell proliferation and expression of phenotypic markers were high on polished surfaces whereas the initial cell recruitment, spreading and bone formation were much better on abraded surface.

\section{Acknowledgements}

One of us, HMTUH, is grateful to the Department of Materials, Queen Mary, University of London, for support with research fees. 


\section{References}

1. R.Srinivassan, B.H.Davis, Zirconia: A review of a super ceramic, in Materials Synthesis and Characterization, D.L.Perry (Ed.) ACS Symp. 1997, pp.147-188.

2. I.Birkby, R.Stevens, Applications of zirconia ceramics, in Advanced Ceramic materials: Applications of advanced materials in a high technology society, H.Mostaghaci (Ed), Key Engineering Materials, 122-1, 1996, pp. 527-551.

3. U. Hempel, T.Hefti, M. Kalbacovan, C. Wolf-Brandstetter, P.Dieter, F.Schlottig, Response of osteoblast-like SAOS-2 cells to zirconia ceramics with different surface topographies, Clin. Oral Impl. Res. 21 (2010) 174-181.

4. R.J. Kohala, M. Bächlea, W.Atta, S.Chaara, B.Altmanna, A.Renzb, F.Butza, Osteoblast and bone tissue response to surface modified zirconia and titanium implant materials, Dent Mater 29 (2013) 763-776.

5. A.Noro, M. Kaneko, I.Murata, M. Yoshinari1, Influence of surface topography and surface physicochemistry on wettability of zirconia (tetragonal zirconia polycrystal), J Biomed Mater Res B: Applied Biomater 101b (2013) Issue 2 356-363.

6. S.Giljean, M.Bigerelle, K.Anselme, Roughness statistical influence on cell adhesion using profilometry and multiscale analysis, Scanning 36 (2014) 2-10.

7. C.Piconi, G.Maccauro, Zirconia as a ceramic biomaterial, Biomaterials 20 (1999) 1-25.

8. X. Feng, L. Jie, M. Jan, Theoretical study of densification of nano-sized 3Y-TZP powder: density-grain growth coupling model, J. Nanopart. Res. 11 (2009) 1719-1727.

9. J.Chevalier, What future for zirconia as a biomaterial? Biomaterials 27 (2006) 535-543.

10. J.Chevalier, L.Gremillard, S.Deville, Low temperature degradation of zirconia and implications for biomedical implants, Ann. Rev. Mater. Res. 37 (2007) 1-32.

11. P.Kohorst, L.Borchers, J.Strempel, M.Stiesch, T.Hassel, F.W.Bach, C.Hubsch, Acta Biomaterialia, 8 (2012) 1213-1220.

12. S.Lawson, Environmental Degradation of zirconia ceramics, J.Euro. Ceram. Soc. 15 (1995) 485-502.

13. M.Ferraris, E.Verne, P.Appendino, C.Moisescu, A.Krajewski, A.Ravaglioli, A.Piancastelli, Coatings on zirconia for medical applications, Biomaterials. 21 (2000) 765-773.

14. K.Anselme, M.Bigerelle, Role of materials surface topography on mammalian cell response, Int. Mater. Rev. 56 (2011) 243-266.

15. M.Bigerelle, K.Anselme, Topography effects of pure titanium substrates on human osteoblast long-term adhesion, Acta Biomaterialia. 1 (2005) 211-222. 
16. J.Meyle, H.Wolburg, A.F. von Recum, Surface micromorphology and cellular interactions, J.Biomater Applics. 7 (1993) 362-374.

17. H. Watanabe, K.Saito, K. Kokubuni, H.Sasaki, M.Yoshinari, Change in surface properties of zirconia and initial attachment of osteoblastlike cells with hydrophilic treatment, Dent Mater J. 31(5): (2012) 806-814.

18. S. Tekeli and T.J.Davies, Net-shape forming of $\mathrm{ZrO}_{2}$-based ceramics and the effect of shaping process on superplastic deformation J. Mater. Sci, 36 (2001) 1873-1877.

19. F.F.Lange, Sinterability of agglomerated powders, J.Amer. Ceram. Soc. 67 (1984) 83-89.

20. G. D. Parfitt, Dispersion of Powders in Liquids with Special Reference to Pigments, Elsevier, U.K., (1969) pp. 81-174.

21. W.Z.Zhu, M. Yan, Effect of Grain Size on the Kinetics of Isothermal Tetragonal to Monoclinic Transformation in $\mathrm{ZrO}_{2}\left(2 \mathrm{~mol}_{\%} \mathrm{Y}_{2} \mathrm{O}_{3}\right)$ Ceramics, J. Euro. Ceram Soc. 17 (1997) 1729-1739.

22. L. Di Silvio, A novel application of two biomaterials for the delivery of growth hormone and its effect on osteoblast. Ph.D Thesis, University of London, 1995.

23. N.Gurav, Biocompatibility testing of resorbable materials using improved in-vitro techniques, Ph.D Thesis, University of London 1997.

24. M.Wieland, M.Textor, B.Chehroudi, D.M.Brunette, Synergistic interaction of topographic features in the production of bone-like nodules on Ti surfaces by rat osteoblasts, Biomaterials 26 (2005) 1119-1130.

25. J.E.Gough, I.Notingher, L.L.Hench, Osteoblast attachment and mineralized nodule formation on rough and smooth 45S5 bioactive glass monoliths, J. Biomed. Res. 68A (2004) 640-650.

26. K.Anselme, M.Bigerelle, B.Noel, A.Iost, P.Hardouin, Effect of grooved titanium substratum on human osteoblastic cell growth, J.Biomed. Res. 60 (2002) 529-540.

27. M.Cehreli, S.Sahin, K.Akca, Role of mechanical environment and implant design on bone tissue differentiation: current knowledge and future contexts, J.Dent. 32 (2004) 123-132.

28. M. N. Aboushelib, E. Osman, I. Jansen, V. Everts, A.J. Feilzer, Influence of a Nanoporous Zirconia Implant Surface of on Cell Viability of Human Osteoblasts, J Prosthodontics 22 (2013) 190-195.

29. T.Mosmann, Rapid colorimetric assay for cellular growth and survival - application to proliferation and cyto-toxicity assays, J. Immunol. Methods 65 (1983) 55-63.

30. C.J.Clifford, S.Downes, A comparative study of the use of colorimetric assays in the assessment of biocompatibility, J.Mater. Sci. Mater. Med. 7 (1996) 637-643.

31. N.Dias, A.Nicolau, G.A.Carvalho, M.Mota, N.Lima, Miniaturization and application of the MTT assay to evaluate metabolic activity of protozoa in the presence of toxicants, J. Basic Microbiol. 39 (1999) 103-108. 
32. R.Hamid, Y.Rotshteyn, L.Rabadi, R.Parikh, P.Bullock, Comparison of alamar blue and MTT assays for high through-put screening, Toxicology in Vitro, 18 (2004) 703-710.

33. S.A.Ahmed, R.M.Gogal, J.E.Walsh, A new rapid and simple non-radioactive assay to monitor and determine the proliferation of lymphocytes, J.Immunol. Methods. 170 (1994) 211-224.

34. G.R.Nakayama, M.C.Caton, M.P.Nova, Z.Parandoosh, Assessment of the Alarma blue assay for cellular growth and viability in vitro, J.Immunol. Methods. 204 (1997) 205-208.

35. M.M.Nociari, A.Shalev, P.Benias, C.Russo, A novel one step, highly sensitive fluorometric assay to evaluate cell-mediate cytotoxicity, J.Immunol. Methods. 213 (1998) 157-167.

36. J.O'Brien, I.Wilson, T.Orton, F.Pognan, Investigation of the Alamar blue (resazurin) fluorescent dye for the assessment of mammalian cell cytotoxicity, Euro. J. Biochem. 267 (2000) 54215426.

37. R.Marom, I.Shur, R.solomon, D.Benayahu, Characterization of adhesion and differentiation markers of osteogenic marrow stromal cells, J.Cell Phys. 202 (2005) 41-48.

38. P.J.Nijweide, E.H.Burger, J.H.M. Feyen, Cells of bone: Proliferation, differentiation and hormonal regulation, Physiol. Revs. 66 (1986) 855-886.

39. A.L.Boskey, Noncollagenous matrix proteins and their role in mineralization, Bone and Mineral. 6 (1989)111-123. 